\title{
An Epidemiological Study of Hyperhidrosis
}

\author{
William Lear, BSc, MD, ${ }^{*}$ Edward Kessler, BA, ${ }^{\dagger}$ Nowell Solish, MD, FRCPC, ${ }^{*}$ and \\ Dee Anna Glaser, $\mathrm{MD}^{\dagger}$
}

BACKGROUND Hyperhidrosis affects approximately $3 \%$ of the population. The nature of those patients presenting for treatment has not been well studied, however.

OBJECTIVE The objective was to perform a descriptive, multicenter study of patterns of patients referred for treatment of focal hyperhidrosis.

METHODS AND MATERIALS A convenience sampling of consecutive patients referred for consideration of BTX-A therapy was surveyed.

RESULTS A total of 508 patient records (266 patients from Canada; 242 from the United States) were reviewed; $62.8 \%$ of those patients were female. The most common presentation was axillary hyperhidrosis in $73.0 \%$ of patients. Most of the patients were moderately to severely affected by their hyperhidrosis, with Hyperhidrosis Disease Severity Scale scores of 3 or 4 . There were trends found of facial and scalp hyperhidrosis affecting more men than women and being triggered by food much more frequently than in other sites of hyperhidrosis.

CONCLUSION This study has demonstrated novel findings, especially in the differing presentations of hyperhidrosis between men and women.

Drs. Solish and Glaser are paid speakers and have performed research for Allergan.

$\mathrm{H}$ yperhidrosis is a disorder characterized as perspiration in excess of the body's physiologic need and can significantly impact one's occupational, physical, emotional, and social life. ${ }^{1,2}$ Hyperhidrosis is delineated into two classifications of either primary or secondary hyperhidrosis. Primary hyperhidrosis is distinguished as a chronic, idiopathic disorder of excessive perspiration in a bilateral, symmetrical manner. ${ }^{3}$ Primary hyperhidrosis has been associated with hyperactivity of the sympathetic nervous system and can affect the palms, soles, axillae, face, and scalp as well as other areas., ${ }^{2,3}$ Secondary hyperhidrosis is due to an underlying condition, such as an infection, endocrine disorders, metabolic disorders, neoplastic diseases, neurologic conditions, spinal cord injuries, cardiovascular disorders, respiratory disorders, anxiety, and stress. ${ }^{2,4}$
Primary hyperhidrosis is a relatively common disorder, affecting nearly $3 \%$ of the population, with the highest prevalence rates among those aged 18 to 54 years. $^{2}$ The most common sites of primary hyperhidrosis are palms, soles, axillae, face, and scalp. ${ }^{4,5}$ Various treatments for hyperhidrosis exist, ranging from topical treatments, iontophoresis, oral anticholinergics, botulinum toxin injections, and surgery. ${ }^{5-8}$ A genetic component has been suggested to contribute to primary hyperhidrosis as family history has been positive in $30 \%$ to $65 \%$ of patients. ${ }^{5,9}$

Much of the current knowledge and research on this disease has been directed on treatment, while few studies have devoted much interest in describing the population subset impacted by hyperhidrosis. Thus, this study set out with the purpose to identify the

${ }^{*}$ The Cosmetic Care and Laser Surgery Center, Women's College Hospital, Toronto, Ontario, Canada; ${ }^{\dagger}$ Department of Dermatology, Anheuser-Busch Institute, Saint Louis University School of Medicine,

St. Louis, Missouri

(C) 2007 by the American Society for Dermatologic Surgery, Inc. • Published by Blackwell Publishing •

ISSN: 1076-0512 • Dermatol Surg 2007;33:S69-S75 • DOI: 10.1111/j.1524-4725.2006.32334.x 
nature of this population subset by identifying common trends and associations. This study was carried out across two clinical populations of Canada and the United States. A retrospective review was conducted on medical records of patients affected by hyperhidrosis that presented to either a specialty hyperhidrosis clinic or a university practice with interests in describing the most common presentations of hyperhidrosis and significant associations.

\section{Methods}

We reviewed the medical records of patients presenting to an urban Canadian hyperhidrosis clinic and a Midwestern American outpatient dermatology clinic between July 2003 and December 2005 for diagnosis and treatment of hyperhidrosis. Information collected from the medical records includes the following: sex, sites of hyperhidrosis, age, date of birth, age of onset, aggravating factors, pre- or postpuberty onset, severity of disease on Hyperhidrosis Disease Severity Scale (HDSS), family history, handedness, tobacco or alcohol use, social status, general habitus, occupation, ethnicity, and past treatment. Data on ethnicity, occupation, social status, tobacco or alcohol use, and general habitus were not collected at the Canadian clinic.

The results were compiled using the Statistical Package for the Social Sciences (SPSS) and analyzed for descriptive statistics. The data were grouped into nominal categories for all variables, except HDSS and age, which were analyzed as ordinal variables. Chi-square statistics were used to test differences between men and women, age of onset, puberty onset, and sites of hyperhidrosis against all other variables. A significance threshold of $p<.05$ was used to determine significance throughout this article.

\section{Results}

In all, a total of 508 patient medical records were reviewed between the Canadian and American clinics (266 in Canada and 242 in the United States).
Taken as a whole, $62.8 \%$ of the patients were female, as $60.5 \%$ of those presenting to the Canadian clinic were female compared to $65.3 \%$ at the American clinic (Table 1). The mean age of the Canadian patients at date of consultation was 30.3

TABLE 1. Patient Demographics

\begin{tabular}{|c|c|c|c|}
\hline \multirow[b]{2}{*}{ Demographic } & \multicolumn{3}{|l|}{$\underline{\text { Clinic }}$} \\
\hline & $\begin{array}{l}\text { American } \\
(\mathrm{n}=242)\end{array}$ & $\begin{array}{l}\text { Canadian } \\
(\mathrm{n}=266)\end{array}$ & $\begin{array}{l}\text { Combined } \\
(\mathrm{N}=508)\end{array}$ \\
\hline \multicolumn{4}{|l|}{ Sex $(\%)$} \\
\hline Female & 65.3 & 60.5 & 62.8 \\
\hline Male & 34.7 & 39.5 & 37.2 \\
\hline \multicolumn{4}{|c|}{ Age at consult (years) } \\
\hline Mean & 28.11 & 30.3 & 29.3 \\
\hline $\mathrm{SD}$ & 12.29 & 10.0 & 11.1 \\
\hline \multicolumn{4}{|l|}{ Age of onset (years) } \\
\hline Mean & 14.05 & - & - \\
\hline \multicolumn{4}{|c|}{ Dominant handedness (\%) } \\
\hline Left & 8.1 & 4.9 & 6.4 \\
\hline \multicolumn{4}{|c|}{ Site(s) of hyperhidrosis* (\%) } \\
\hline Axillary site & 78.5 & 68.0 & 73.0 \\
\hline Palmar & 47.9 & 44.0 & 45.9 \\
\hline Plantar (soles) & 44.6 & 38.0 & 41.1 \\
\hline Face or scalp & 23.6 & 22.9 & 22.8 \\
\hline Groin & 12.4 & 6.4 & 9.3 \\
\hline Additional $^{\dagger}$ & 13.6 & 6.0 & 9.6 \\
\hline \multicolumn{4}{|c|}{ Severity on HDSS (\%) } \\
\hline 4 & 79.1 & 35.0 & 55.2 \\
\hline 3 & 20.0 & 47.7 & 35.0 \\
\hline 2 & 0.9 & 16.9 & 9.6 \\
\hline 1 & 0.0 & 0.4 & 0.2 \\
\hline \multicolumn{4}{|l|}{ Family history (\%) } \\
\hline Positive & 47.5 & 40.2 & 43.7 \\
\hline Negative & 35.0 & 59.8 & 48.0 \\
\hline Unaware & 17.5 & - & - \\
\hline \multicolumn{4}{|l|}{ Past treatment (\%) } \\
\hline Over-the-counter & 83.9 & - & - \\
\hline $\begin{array}{l}\text { Topical aluminum } \\
\text { chloride }\end{array}$ & 66.1 & 73.7 & 70.1 \\
\hline $\begin{array}{l}\text { Oral anticholiner- } \\
\text { gic }\end{array}$ & 11.1 & 8.3 & 9.6 \\
\hline $\begin{array}{l}\text { Botulinum toxin } \\
\text { type } A\end{array}$ & 8.3 & 18.8 & 13.8 \\
\hline Iontophoresis & 11.9 & 10.5 & 11.2 \\
\hline Surgery & 0.4 & 4.5 & 2.6 \\
\hline None & 3.7 & 18.8 & 11.6 \\
\hline
\end{tabular}

*Each category does not exclude additional sites that may also be involved.

Additional site(s) include patients presenting with (patients are included only once even if multiple sites affected): back, chest, abdomen, forearm, genitals, and lower extremities. 
years (SD, 10.0 years) whereas those presenting to the American clinic were a mean age of 28.1 years (SD, 12.29 years) with a median age of 25 years (see Table 1). The mean age of onset of hyperhidrosis for the American patients was 14 years (median, 13.0 years; SD, 8.25 years; see Table 1 ).

For both the American and the Canadian clinics, the most common affected sites were axillary, palmar, and plantar sites (Table 1). An overwhelming majority of the Canadian and American patients were moderately or severely affected by hyperhidrosis, rating their disease as either 3 or 4 on the HDSS (Table 1).

Many patients noted a positive family history, with $43.7 \%$ of the pooled patient population reporting a relative to be affected by hyperhidrosis (Table 1 ). Most patients of either nationality had tried some form of treatment before the consult visit, such as topical aluminum chloride $\left(\mathrm{AlCl}_{3} ; 70.1 \%\right.$ of the combined clinics) or botulinum toxin type A subcutaneous injections $(13.8 \%$ of the combined clinics; see Table 1 ). Only $6.4 \%$ of the combined clinics' patients reported left-handedness, with $4.9 \%$ of the Canadian patients indicating left-handedness compared to $8.1 \%$ of the American patients (see Table 1 ).

An overwhelming majority of the American patients were Caucasian $(87.9 \%)$, followed by AfricanAmericans (8.4\%), Asians (1.7\%), Hispanics $(0.8 \%)$, Indian $(0.8 \%)$, and other $(0.4 \%$; Table 2$)$. The American patient population was divided categorically as (in order of descending frequency): students, business workers, professionals, home workers, laborers, retirees, disabled persons, travelers, security, and unemployed persons (Table 2). Some of the most common aggravating factors reported by patients of either clinic were stress, heat, and exercise (Table 3).

Several factors were noted to be significant in the associations of affected site(s) with gender and aggravating factors in both the Canadian and the American clinics. In both countries, it was noted that

\section{TABLE 2. Ethnicity and Occupation*}

\begin{tabular}{|c|c|}
\hline \multicolumn{2}{|l|}{ Ethnicity (\%) } \\
\hline Caucasian & 87.9 \\
\hline African-American & 8.4 \\
\hline Asian & 1.7 \\
\hline Hispanic & 0.8 \\
\hline Indian & 0.8 \\
\hline Other & 0.4 \\
\hline \multicolumn{2}{|l|}{ Occupation (\%) } \\
\hline $\begin{array}{l}\text { Student (elementary, high school, } \\
\text { college, or graduate) }\end{array}$ & 43.4 \\
\hline $\begin{array}{l}\text { Business (business professionals, office } \\
\text { workers, salesmen/women, accountants, } \\
\text { processors, representatives, designers, } \\
\text { artists, receptionists, reporters, stylists, } \\
\text { computer workers) }\end{array}$ & 23.8 \\
\hline $\begin{array}{l}\text { Professional (teachers/professors, attorneys, } \\
\text { physicians, nurses, professional assistants, } \\
\text { therapists, researchers, administrators, } \\
\text { engineers) }\end{array}$ & 15.1 \\
\hline $\begin{array}{l}\text { Home (housewives, at-home mothers, } \\
\text { homemakers) }\end{array}$ & 5.0 \\
\hline $\begin{array}{l}\text { Labor (construction, factory workers, } \\
\text { grocery workers, technicians, pipefitters) }\end{array}$ & 4.2 \\
\hline Retired & 2.5 \\
\hline $\begin{array}{l}\text { Drive/travel (stewards/stewardess, couriers, } \\
\text { truck drivers) }\end{array}$ & 1.7 \\
\hline $\begin{array}{l}\text { Security (firemen/women, police officers, } \\
\text { and security officers) }\end{array}$ & 1.7 \\
\hline Unemployed & 1.2 \\
\hline Disabled & 0.84 \\
\hline
\end{tabular}

* Data available for American clinic only.

men were significantly more likely to present with facial or scalp hyperhidrosis. Men presenting to the American clinic were also found to be significantly more likely to present with "additional areas" of hyperhidrosis than women (Table 4). "Additional areas" refer to the back, chest, abdomen, forearm, genital, and lower extremities. In contrast, women presenting to the Canadian clinic were significantly more likely to have plantar hyperhidrosis than men, but at a rate similar to American women (Table 4). Also when considering isolated affected sites of hyperhidrosis, women in the American clinic were significantly more likely to present with isolated axillary hyperhidrosis than men. Moreover, women presenting to the Canadian clinic showed a trend to present more with axillary hyperhidrosis. This may have reflected the higher likelihood of women in the 
TABLE 3. Aggravating Factors*

\begin{tabular}{|c|c|c|}
\hline \multirow[b]{2}{*}{ Factor } & \multicolumn{2}{|l|}{ Clinic } \\
\hline & $\begin{array}{l}\text { American } \\
(\mathrm{n}=242)\end{array}$ & $\begin{array}{l}\text { Canadian } \\
(\mathrm{n}=266)\end{array}$ \\
\hline Anxiety or stress & 75.2 & 69.5 \\
\hline Heat & 61.6 & 64.7 \\
\hline Exercise & 55.4 & 43.2 \\
\hline Food & - & 12.8 \\
\hline Sleep & 16.5 & - \\
\hline Other $^{\dagger}$ & 14.5 & - \\
\hline None & 8.7 & - \\
\hline $\begin{array}{l}\text { Other }{ }^{\dagger} / \text { no known } \\
\text { factors }\end{array}$ & 23.1 & 24.1 \\
\hline
\end{tabular}

*Data are reported as percent.

'Other aggravating factors refer to winter season, humidity, cold, caffeine, movement, sitting, clothing, writing, working, and social situations.

Canadian clinic to have already tried $\mathrm{AlCl}_{3}$ before consultation.

In the American clinic, patients that presented with hyperhidrosis of palms, soles (plantar), or a combination of palms and soles (palmoplantar) were significantly more likely to list stress and anxiety as aggravating factors. Patients that presented with fa- cial and scalp hyperhidrosis were significantly more likely to list food, exercise, and heat as aggravating factors.

Other factors noted to be significant in the American clinic concerned family history of hyperhidrosis.

Patients that presented with palmar, plantar, or palmoplantar hyperhidrosis were significantly more likely to have a positive family history of hyperhidrosis. Patients that reported the onset of hyperhidrosis before the age of 20 years were significantly more likely to have a positive family history of hyperhidrosis than those reporting the onset of hyperhidrosis after the age of 20 years old.

Also in the American clinic, patients presenting with axillary hyperhidrosis were significantly more likely to have a postpuberty onset of hyperhidrosis. In a similar manner, when considering isolated affected sites of hyperhidrosis, a postpuberty onset was significantly more likely in patients presenting with isolated axillary hyperhidrosis. In contrast, patients presenting with isolated palmoplantar hyperhidrosis were significantly more likely to have a prepuberty onset of hyperhidrosis.

TABLE 4. Cross-section of Site(s) of Hyperhidrosis and Hyperhidrosis Disease Severity Scale (HDSS) Scores by Sex*

\begin{tabular}{|c|c|c|c|c|}
\hline & \multicolumn{4}{|l|}{ Clinic } \\
\hline & \multicolumn{2}{|l|}{ American } & \multicolumn{2}{|l|}{ Canadian } \\
\hline & Male & Female & Male & Female \\
\hline \multicolumn{5}{|l|}{ Site $^{\dagger}$} \\
\hline Axillary & $63 / 84(75.0)$ & $127 / 158(80.4)$ & $65 / 105$ (61.9) & $116 / 161(72.0)$ \\
\hline Palmar & $46 / 84(54.8)$ & 70/158 (44.3) & 41/105 (39.0) & $76 / 161(47.2)$ \\
\hline Face or scalp & $26 / 84(31.0)^{\ddagger}$ & $23 / 158(14.6)^{\ddagger}$ & $39 / 105(37.1)^{\ddagger}$ & $20 / 161(12.4)^{\ddagger}$ \\
\hline Plantar (soles) & $37 / 84(44.0)$ & 71/158 (44.9) & $27 / 105(25.7)^{\ddagger}$ & $74 / 161(46.0)^{\ddagger}$ \\
\hline Groin & $10 / 84(11.9)$ & $20 / 158(12.7)$ & $6 / 105(5.7)$ & $11 / 161(6.8)$ \\
\hline Additional areas ${ }^{\S}$ & $18 / 84(21.4)^{\ddagger}$ & $15 / 158(9.5)^{\ddagger}$ & $7 / 105(6.6)$ & $9 / 161(5.6)$ \\
\hline \multicolumn{5}{|l|}{ HDSS score } \\
\hline 1 or 2 & 1/77 (1.3) & $1 / 158(0.7)$ & $30 / 105(28.6)$ & $16 / 161(9.9)$ \\
\hline 3 or 4 & 76/77 (98.7) & 157/158 (99.3) & 75/105 (71.4) & $145 / 161(90.1)$ \\
\hline
\end{tabular}


TABLE 5. Cross-section of Site(s) of Hyperhidrosis by Age of Onset*

\begin{tabular}{lllc} 
& \multicolumn{3}{l}{ Age of onset (years) } \\
\cline { 2 - 4 } Site $^{\dagger}$ & $0-11$ & $12-19$ & $20-53$ \\
\hline Axillary & $50(27.2)$ & $101(54.9)^{\ddagger}$ & $33(17.9)$ \\
Palmoplantar & $53(58.2)^{\ddagger}$ & $33(36.3)$ & $5(5.5)$ \\
Palmar & $59(51.8)^{\ddagger}$ & $45(39.5)$ & $10(8.8)$ \\
Plantar (soles) & $59(55.7)^{\ddagger}$ & $42(39.6)$ & $5(4.7)$ \\
Face or scalp & $17(37.0)$ & $20(43.5)$ & $9(19.6)$ \\
Groin & $10(33.3)$ & $18(60.0)$ & $2(6.7)$ \\
Additional areas & $10(31.3)$ & $15(46.9)$ & $7(21.9)$ \\
\hline
\end{tabular}

*Data available for American clinic only. Data are reported as number (\%).

${ }^{\dagger}$ For each affected site, other sites may also be involved. For those patients with multiple affected sites, age of onset does not specify which site of hyperhidrosis occurred first and which occurred at a later date.

${ }^{\ddagger}$ Statistically significant, $p<.05$.

${ }^{\$}$ Additional areas include patients presenting with (patients are included only once even if multiple sites affected): back, chest, abdomen, forearm, genitals, and lower extremities.

The younger age of onset group (before the age of 11 years) was significantly more likely to present with hyperhidrosis of the palms, soles, or combined palmoplantar sites. Patients reporting onset between the ages of 12 and 19 years were significantly more likely to present with axillary hyperhidrosis (Table 5).

Of those presenting to the Canadian locale, higher HDSS scores were seen in women, but the scores did not differ among sites of hyperhidrosis. HDSS scores were significantly higher among patients having tried prior treatments with aluminum chloride and oral therapies. Lower HDSS scores were significantly associated with no prior treatments (not shown).

American men and women had similar HDSS scores, both higher than the Canadians, but did not significantly differ between the sexes.

\section{Discussion}

The patient population in our study differed with the population described in the US prevalence study by Strutton and colleagues. ${ }^{2}$ In particular, our study found an earlier mean age of onset of hyperhidrosis (14 years) compared that reported in the US prevalence study (25 years). Interestingly, the mean age of our patients presenting with hyperhidrosis was 29.3 years (28.1 years in the American clinic and 30.3 years in the Canadian clinic) in contrast to the study by Strutton and colleagues ${ }^{2}$ in which the mean age of their study subjects was 40 years.

In addition, we encountered a more severely affected group of hyperhidrosis patients than expected in general. The majority of the patients presenting to the Canadian site reported a HDSS score of 3 whereas the majority of patients in the American clinic rated their hyperhidrosis with maximum severity ( 4 of 4 ) on the HDSS, which rates the disease as intolerable and always interferes in their life. This contrasts with the US prevalence study, which reported the majority of the responders with excessive sweating rated their disease as a 2 (tolerable, sometimes interferes) on the HDSS. The majority of the presenting patients to either clinic had received numerous therapies before consultation; such a population would be expected to have a higher HDSS score than an average hyperhidrosis patient in the community (see Table 1). The difference between the presenting patients in this study versus those screened in the study by Strutton and colleagues ${ }^{2}$ may be due to our study patients actively seeking treatment for their condition while those described in the US prevalence study were assessed as the population at large.

This reasoning may also be extended to explain the higher percentage of patients in this study affected by axillary hyperhidrosis $(73.0 \%$ of the combined clinic populations vs. $50.8 \%$ in the study by Strutton and coworkers $^{2}$ study). In addition, there was a difference in the presentation of sex in this study; female patients presented in higher frequencies in both the Canadian and the American sites, $62.8 \%$ of the combined clinics (Table 1). Strutton and colleagues ${ }^{2}$ found no difference among sex and prevalence rates of hyperhidrosis, but noted the women report their hyperhidrosis to physicians at higher rates. In addition, a subgroup analysis of the Canadian patients 
revealed that the women had higher HDSS scores than men, indicating that they were more severely affected than males. In the study by Strutton and coworkers, ${ }^{2}$ overall female HDSS scores are quite similar to those of men, making a fundamental difference in interpretation of hyperhidrosis severity between men and women unlikely. As such, our finding of such a difference in presentation may be reflected in the vast disparity between women and men in discussing their condition with a physician. Pursuing this suggestion leaves us to consider that there is some subset of the men affected by hyperhidrosis that have not been referred or sought treatment for their condition.

In light of this idea, this study found several differences between sexes among the other variables collected. One difference between men and women related to the affected site(s) of presentation. In Table 4, the analysis reveals that men were more likely to present with facial or scalp hyperhidrosis, or hyperhidrosis in "additional areas," such as the chest, back, or lower extremities, than were women. Facial and scalp hyperhidrosis in these men was aggravated significantly more frequently by food, heat, and exercise than hyperhidrosis of other sites. Although a full understanding of the pathophysiology of hyperhidrosis is lacking, there is evidence implicating a heightened sympathetic activity through the T2 and T3 ganglia resulting in palmar hyperhidrosis. ${ }^{5}$ To some extent, the degree of autonomic dysfunction can be quantified by the rate of rewarming of the hands after immersion in an ice bath, with a slower rate of rewarming being indicative of excessive sympathetic activity. ${ }^{9}$ Further work has elucidated sex differences in these autonomic responses between men and women, with women showing slower baseline rewarming responses than men. ${ }^{10}$ Although we did not find that more women presented with palmar hyperhidrosis in our population, there may be further sex differences in autonomic responses that predispose each sex to have a higher propensity to develop focal hyperhidrosis in certain sites, such as the facial hyperhidrosis more prevalent in men.
In the American clinic, although $47.5 \%$ of the patients were able to identify a relative with hyperhidrosis, $35.0 \%$ reported a negative family history and $17.5 \%$ reported not knowing their family history in regard to hyperhidrosis. Hyperhidrosis in family members may be underreported due to the social ramifications and efforts to conceal its presence by affected family members. American patients who reported an age of onset before 20 years of age were found to be more likely to have a positive family history of hyperhidrosis than those with a later age of onset. This analysis may be confounded, however, by the small number of patients reporting a later age of onset (39 patients) compared to those reporting an onset before the age of 20 (196 patients).

As was expected in this study, American patients stating an age of onset between 0 and 11 years were more likely to present with palmar, plantar, or palmoplantar hyperhidrosis, whereas those reporting an age of onset between 12 and 19 years were more likely to present with axillary hyperhidrosis (Table 5). Supporting this expectation of postpuberty onset of axillary hyperhidrosis, it was also noted that a postpuberty onset was more likely with patients presenting with axillary hyperhidrosis and hyperhidrosis isolated only to the axillae. To contrast, a prepuberty onset was found to be more likely of patients presenting with isolated palmoplantar hyperhidrosis.

In summary, this is the first large descriptive study of patients seeking diagnosis and treatment of hyperhidrosis, which has demonstrated novel findings. In contrast to those with excessive sweating in the community, patients seeking medical attention are severely affected by their condition. As previously reported, axillary hyperhidrosis accounts for the majority of bodily presentation sites. Despite past reports of no differences between men and women in regard to the prevalence of excessive sweating, our study found distinct differences between men and women in reference to facial or scalp hyperhidrosis and how often they seek medical care for their hyperhidrosis. There was a clear pattern in the body site affected by the hyperhidrosis 
and the age onset and family history. And although there were some small differences between the Canadian and American patients, overall, the similarities in sex, age seeking treatment, age of onset, and body sites affected were remarkable. Hopefully, these data will help clinicians and future investigators to better understand the hyperhidrosis population.

\section{References}

1. Lowe N, Campanati A, Bodokh I, et al. The place of botulinum toxin type A in the treatment of focal hyperhidrosis. Br J Dermatol 2004;151:1115-22.

2. Strutton DR, Kowalski JW, Glaser DA, Stang PE. US prevalence of hyperhidrosis and impact on individuals with axillary hyperhidrosis: results from a national survey. J Am Acad Dermatol 2004;51:241-8.

3. Hornberger J, Grimes K, Naumann M, et al. Recognition, diagnosis, and treatment of primary focal hyperhidrosis. J Am Acad Dermatol 2004;51:274-86.

4. Eisenach JH, Atkinson JL, Fealey RD. Hyperhidrosis: evolving therapies for a well-established phenomenon. Mayo Clin Proc 2005;80:657-66.
5. Haider A, Solish N. Focal hyperhidrosis: diagnosis and management. Can Med Assoc J 2005;172:69-75.

6. Naumann M, Hamm H. Treatment of axillary hyperhidrosis. Br J Surg 2002;89:259-61.

7. Baumann L, Slezinger A, Halem M, et al. Double-blind, randomized, placebo-controlled pilot study of the safety and efficacy of Myobloc (botulinum toxin type B) for the treatment of palmar hyperhidrosis. Dermatol Surg 2005;31:263-70.

8. Glogau RG. Treatment of hyperhidrosis with botulinum toxin. Dermatol Clin 2004;22:177-85.

9. Ro KM, Cantor RM, Lange KL, Ahn SS. Palmar hyperhidrosis: evidence of genetic transmission. J Vasc Surg 2002;35:382-6.

10. Fronek KS, Schmelz M, Kruger S, et al. Effects of gender and level of surgical sympathetic block on vasoconstrictor function. Clin Auton Res 2003;13:(Suppl 1):74-8.

11. Schick CH, Fronek K, Held A, et al. Differential effects of surgical sympathetic block on sudomotor and vasoconstrictor function. Neurology 2003;60:1770-6.

Address correspondence and reprint requests to: Dr. Nowell Solish, The Cosmetic Care and Laser Surgery Center, Women's College Hospital, 76 Grenville Street, 8th Floor, Toronto, ON, Canada M5S 1B2, or e-mail:n.solish@utoronto.ca. 